\title{
Structural effects of FRC creep
}

\author{
Giovanni Plizzari $\cdot$ Pedro Serna
}

Received: 15 November 2018/Accepted: 22 November 2018/Published online: 3 December 2018

(C) The Author(s) 2018, corrected publication 2019

\begin{abstract}
Research studies in the last 20 years allowed to obtain reliable rules for designing structures made of fiber reinforced concrete (FRC). However, design aspects like the long-term behavior of FRC, especially when synthetic fibers are adopted, require further research. Long-term behavior includes aging and creep. Aging represent the change of fiber properties into the concrete environment, which may reduce the structural bearing capacity; when present, it is an important issue for the structural safety, especially when fibers are the only reinforcement. Aging of fibers must be proven by experimental tests. Creep is a complex phenomenon, roughly considered by building codes even for traditional reinforced concrete (RC) structures. The introduction of fibers do not change anything in concrete matrix and, before cracking, in the material concrete creep behavior is not expected any change. After cracking, the structural effect of FRC creep depends on the degree of structural redundancy and on the presence of rebars since creep produces a stress redistribution in the structure or from FRC to the rebars. When FRC postcracking resistance is necessary for equilibrium
\end{abstract}

G. Plizzari

University of Brescia, Brescia, Italy

e-mail: giovanni.plizzari@unibs.it

P. Serna $(\square)$

Universitat Politècnica de València, València, Spain

e-mail: pserna@cst.upv.es requirements, in structures with cracked sections in service conditions the structural deferred response has to be analyzed by considering the FRC creep behavior. When FRC is used for resisting secondary actions and rebars are present for equilibrium requirements, the response of a FRC element (with rebars and fibers) will be identical to a conventional RC; FRC contributes by controlling the crack development under both short and long term loading.

Keywords Fiber reinforced concrete - FRC creep · Long term behavior $\cdot$ Fiber aging $\cdot$ Structural behaviour

\section{Introduction}

Fiber reinforced concrete (FRC) is now entering extensively into the market due to the availability of structural codes as the fib Model Code 2010 (MC2010) [1], the German Code [2], the Italian Code [3] the ACI 318 [4] and incoming codes under development in several Countries, including the Eurocode 2 [5]. In fact, research studies developed during the last 50 years provided an extensive knowledge on structural behavior of FRC and allowed to have reliable and safe design rules. For all these reasons, FRC has been already used for several applications, including industrial floors, tunnel linings, elevated slabs and for different precast elements [6, 7]. 
However, some design aspects are not well known yet and require further research. Even though fiber are usually adopted for replacing (at least part of) conventional reinforcement, fibers may be added to ordinary reinforced concrete (RC) elements as they reduce cracking phenomena [8] and may influence the structure durability. In any case, the minimum required cover should not change as it depends on the concrete porosity which is a matrix dependent property.

Among the open issues, there are the fiber efficiency, due to both orientation and distribution, as well as the long-term behavior of FRC [9, 10]. The latter includes aging and creep. In particular, FRC aging refers to (1) the change of fiber properties in the cementitious environment where fibers can be in contact with possible aggressive agents (also due to cracks) or to (2) degradation of the bond behavior between matrix and fiber. Among the aging effects, it should be mentioned that some synthetic materials might become brittle with time [11]. Another typical example of aging is represented by some glass fibers that can generate reactions due to concrete alkalinity; to overcome this issue, alkali-resistant (AR) glass fibers, able to work in those conditions, are now available into the market [12]. In summary, FRC aging may not be accepted for practical applications when it can seriously influence structural safety.

Creep is a complex phenomenon considered only with rather simplified approaches by building codes even for usual RC structures. The creep behavior of ordinary concrete structures is usually addressed in structural codes by stating that the steel reinforcement does not experience deferred strains and that all changes over time are due to the creep of concrete that mainly occurs in the compressed area of the section.

Concrete creep in compression is included in the MC2010 materials chapter [1]. Data are based on specific tests [13] and consider the influence of exposure parameters (like humidity and temperature) or the element size, for providing a time dependent creep coefficient " $\varphi$ " (MC2010, §5.1.9.4.3).

At the structural level, stresses produce strains at short term and creep induces a time dependent strain increase. In redundant structures, due to boundary conditions (external restrictions, supports stiffness...), a local stress relaxation as well as a transmission of stresses to less demanded sections occur. Depending on the degree of redundancy either creep or stress relaxation will need to be considered in a structure.

The application of the creep concepts in structural design is often considered as a reduction of the modulus of elasticity (MC2010, Eq 7.6-18). Furthermore, a time dependent $\beta$ coefficient is applied to determine structural deflections (see Eq 7.6-16 of MC2010). The $\beta$ coefficient can be either 0.5 or 1 for short or long term loading, respectively. Another case were creep is considered in design is related to the crack width, where another (but different) $\beta$ parameter is included (see Eq 7.6-6 of MC2010), with low consideration of influencing parameters. No more creep issues are mentioned in structural codes.

This limited presence of creep in building codes for reinforced concrete (RC) elements (without fibers) is related to the very complex phenomena that make creep very difficult to model and, especially, hardly predictable in current structures where environmental conditions are not known a priori and continuously change.

As far as FRC is concerned, no creep structural issues are considered in MC2010 with the exception of creep of the fiber material. The introduction of a moderate dosage of fibers into the concrete does not change anything in the cementitious matrix before cracking and no changes are expected in creep behavior with respect to ordinary concrete, neither in compression nor in tension [14]. After cracking, there is major consensus in relation to the main sources for time-dependent strains of FRC under tension or bending, namely: (1) creep in the compression zone: (2) time-dependent bond strains between concrete and fibers crossing the cracks and (3) creep of the fiber material. When referring to a hybrid reinforcement (fibers + rebars), the time dependent deformations are also affected by the time dependent rebar-matrix slips. Nevertheless, no proposal about the design criteria in FRC are included in the building codes available so far.

In order to better analyze the influence of this phenomenon in FRC applications, RILEM activated a Technical Committee (TC 261-CCF) that organized a first workshop [15] to discuss the knowledge in the field and the state of the art. The technical committee also made a comparison between different test methods for proposing a standard test method for FRC creep, when necessary [16-18]. 
In the present paper, some aspects related to long term behavior of FRC structures are analyzed with the aim of clarifying the effect of FRC creep on the structural behavior of the most diffused applications nowadays. The use of fibers for different reasons as fire (spalling), shrinkage cracking, aesthetic aspects or other not structural considerations are out of the scope of this paper.

\section{Limits for the FRC use}

\subsection{Fiber material}

MC2010 allows the use of fibers made of different materials like steel, polymers, carbon, glass or natural materials, but recognizes that general rules are mainly based on experiences with steel fibers. However, MC2010 proposes a FRC classification (typing) based on mechanical properties but it states a clear warning on the use of fibers made with materials whose properties are influenced by time and/or hygro-thermal phenomena. Nevertheless, MC2010 does not define criteria to evaluate these critical aspects so that they are under the responsibility of the designer and of the construction company. The criteria to evaluate the time dependent behavior should be supported by specific standards and, when possible, by experimental tests.

In addition to creep, aging may provoke a possible fiber deterioration that reduces the bearing capacity of the structural elements; therefore, FRC aging may not be accepted for practical applications when it can seriously influence structural safety.

Standard EN 14889-2 [19], referring to synthetic fibers, requires to verify the long-term behavior by testing the resistance to deterioration for moisture and alkalis present in cement paste, according to EN 14030 [20] or EN 14649 [21]. These test were initially proposed for glass fibers as accelerated tests to provide material degradation into a specific tolerance and allow to evaluate if a fiber is "adequate or not for structural concrete", assuming that the possible effect in the mechanical performance at the end of the service life is negligible.

In summary, the FRC supplier should guarantee properties and limits of applicability throughout the expected service life.

\subsection{FRC mechanical properties}

From a mechanical point of view, according to MC 2010 [1] FRC is also classified for its tensile resistance by considering the post cracking behavior through the residual strength at different cracking levels. A minimum performance class " $1.0 \mathrm{a}$ " must be guaranteed if FRC aims to substitute (even part of) conventional reinforcement; this means that the minimum value for $f_{R I k}$ is $1.0 \mathrm{MPa}$ and for $f_{R 3 k}$ is $0.5 \mathrm{MPa}$. In addition, it is required that:

$f_{R 1 k} \geq 0.4 f_{L k}$

$f_{R 3 k} \geq 0.5 f_{R 1 k}$

where:

- $f_{R l k}$ is the post-cracking resistance (characteristic value) corresponding to a Crack Mouth Opening Displacement (CMOD) of $0.5 \mathrm{~mm}$, according to EN 14651 [22];

- $f_{R 3 k}$ is the post-cracking resistance corresponding to a Crack Mouth Opening Displacement (CMOD) of $2.5 \mathrm{~mm}$, according to EN 14651 [22];

- $f_{L k}$ is the Limit of Proportionality according to EN 14651 [22];

The minimum requirements are independent of fiber material and can be achieved through a proper mix design which takes into account the properties of concrete and of fibers; some shortcomings in the properties of the selected fiber can be compensated by an increase of the fiber dosage.

However, the ratio $f_{R 3 k} / f_{R l k}$ mainly depends on the fiber material properties and on the anchorage system (fibers hooked, crimped, twisted, etc....); structural designers must be aware of this requirement as they can guide in the choice of the type of fiber to be used.

\subsection{Structural behavior}

FRC can be used as structural material for:

- enhancing crack behavior which is particularly important at Serviceability Limit States (SLS) and also for durability requirements;

- replacing all or part of the conventional reinforcement for structural capacity at Ultimate Limit States (ULS). 
Model Code 2010 [1] also requires that, when FRC assumes a structural function, ductility must be guaranteed at the structural level; accordingly, at least one of the two following structural requirements must be verified (MC2010 7.7.2):

$\delta_{\mathrm{u}} \geq 20 \delta_{\mathrm{SLS}}$

$\delta_{\text {peak }} \geq 5 \delta_{\text {SLS }}$

were $\delta_{\mathrm{u}}$ is the ultimate displacement of the structure, $\delta_{\text {peak }}$ is the displacement at peak load and $\delta_{\text {SLS }}$ is the displacement expected under service conditions.

\section{FRC and structural behavior}

Ductility and structural requirements refer to instantaneous actions as well as to long term ones, over the whole service life. It is clear that creep phenomena should be considered only for sustained loads ("quasi permanent solicitations") and not for temporary loading.

In the next sections, some structural aspects related to typical FRC applications will be analyzed, with particular attention to long term behavior; the aim is to consider a wide typology of representative cases that can help to apply the concepts in a more general way.

It should be mentioned that FRC is better used for structural elements with high degree of redundancy, which can take advantage from stress redistribution. However, in this paper other cases will be considered and some recommendations will be introduced, when necessary.

\subsection{FRC as minimum reinforcement}

When FRC is adopted for substituting minimum reinforcement requirements, it is expected that the structure will work in service without any crack; in this case, loads do not produce cracks as they are always lower than the first crack load; FRC as minimum shear reinforcement is a significant example. Possible cracks produced by accidental actions usually occurs well beyond service conditions. Therefore, when using FRC as minimum reinforcement, creep in cracked sections is not a main issue.

\subsection{Linear elements}

When considering creep in cracked sections of linear elements (1D), a distinction must be made between structures without reinforcing bars, where FRC is responsible for equilibrium, and structures with conventional rebars, where FRC contributes to equilibrate external actions (Fig. 1).

In the first case long-term behavior of FRC is of paramount importance for structural safety while, in the second case, a distinction must be made between different structural aspects.

\subsubsection{Bending in linear elements without conventional reinforcement}

When only FRC (without rebars) is in charge of equilibrium requirements in cracked conditions, the structural deferred response has to be analyzed by considering the creep behavior and it should be mandatory to guarantee crack openings (over the whole service life) lower than the maximum allowed by exposure conditions. In this context, by considering the partial safety factors adopted for serviceability and ultimate limit states, the quasi-permanent load combination in service will never be higher than $40-50 \%$ of the actual residual capacity of the structure.

Moreover, for ductility requirements (Eqs. 3 and 4) a strain hardening behavior in bending must be guaranteed at the structural level; the latter generally requires values of $f_{R 3 k}$ and $f_{R 1 k}$ well above of $\mathrm{f}_{\mathrm{L}}$ (i.e. EN 14651), also considering fiber efficiency and size effects as load deflection response is size dependent. The previous requirements often imply to use high performance FRCs so that the use of conventional reinforcement may represent a convenient solution for practice; therefore, in the particular case of linear elements, FRC without conventional reinforcement does not represent the best solution in most cases.

However, when FRC creep has to be verified for structural behavior, proper creep tests have to be carried out.

Most of the test proposed for evaluating creep in FRC are based on beam tests [23-25], both on notched or un-notched beams with the load applied in the postcracking phase with a test configuration similar to the EN 14651 [16]. Other test methodologies have been suggested [26, 27], but the difficulty of execution limited the experiences so that few data are available 


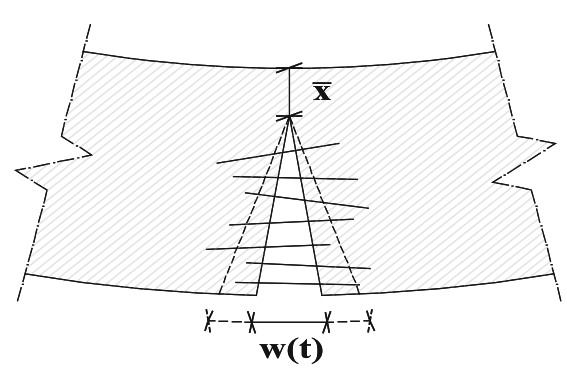

(a)

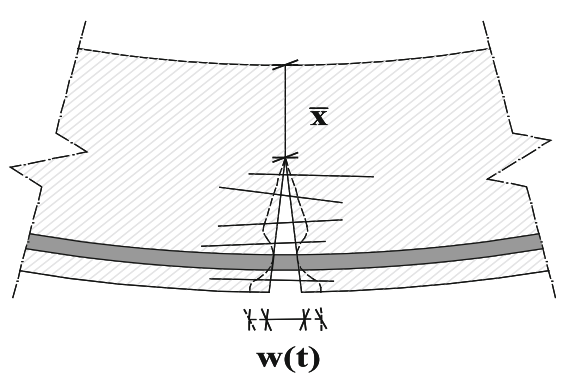

(b)

Fig. 1 Response in a FRC cracked section a with only fibers, b with also rebars

so far. In addition, most of the tests were carried out with high load levels $\left(F_{\mathrm{a}} / F_{\mathrm{w}}\right.$ in Fig. 2$)$, not representative of the quasi-permanent load combination significant for practice. This was mainly due to the need of collecting significant results in an acceptable testing time since low load levels require longer test times. The load level adopted during the test is a key factor determining flexural creep behavior on pre-cracked specimens. Results published on steel fiber reinforced concrete (SFRC) show that, even for high load levels $\left(F_{\mathrm{a}} / F_{\mathrm{w}} \sim 60 \%\right)$, the measured creep coefficients remains small $(<1)$ after 90 days of sustained load [16]. For higher load ratios responses with tertiary creep were found [28] and other factors, like slenderness of steel fibers, have an important synergic effect [29].

However, when analyzing the post creep behavior, it should be highlighted that, if the crack opening stays within acceptable limits, the residual strength and the general load vs crack opening response fits well the curves obtained during monotonic short term loading (Fig. 3); as such, the residual structural capacity is not significantly influenced by creep.

In summary, in linear elements without conventional rebars long term behavior of FRC is of paramount importance for structural safety. Deformations as well as crack openings could increase due to FRC creep so that the latter has to be carefully considered. Concrete compressive strength significantly influences the flexural creep behavior on precracked specimens because it reduces the creep in compressed zone and enhances fibre-concrete bond.

However, more tests are needed to confirm the available results, in order to better analyze low load levels and low initial crack opening, to better predict with the long-term evolution over the whole service life, and to explore other types of fibers.
Fig. 2 Typical loading history in a creep test on cracked specimens [16]

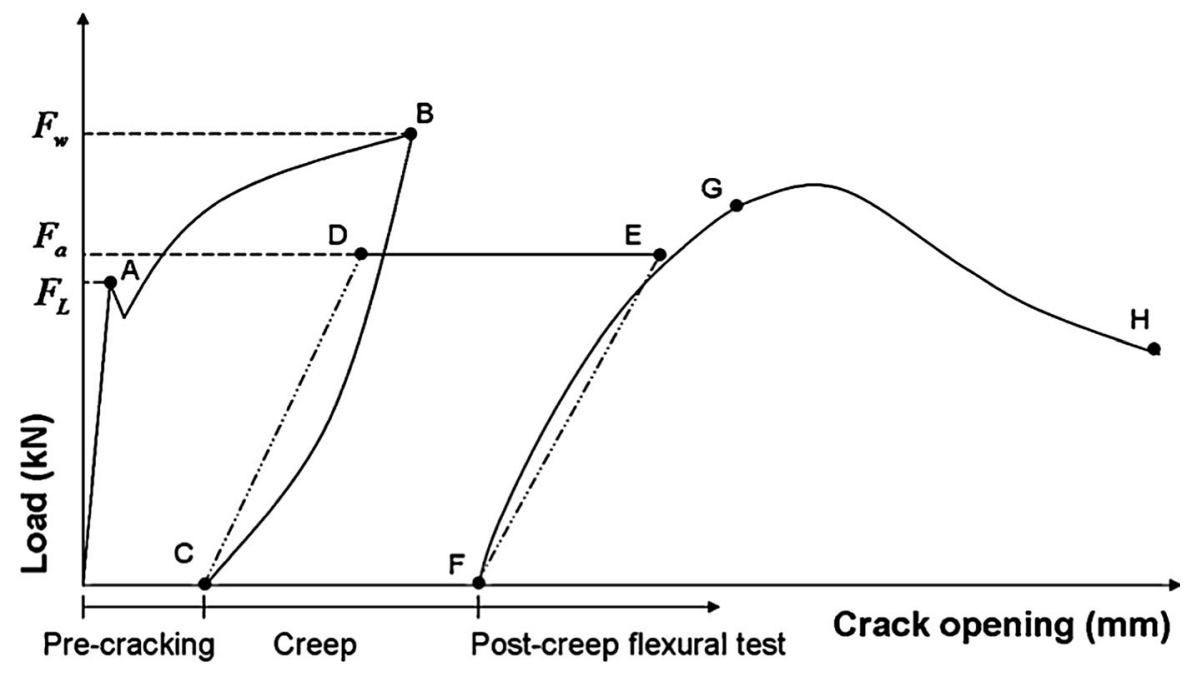



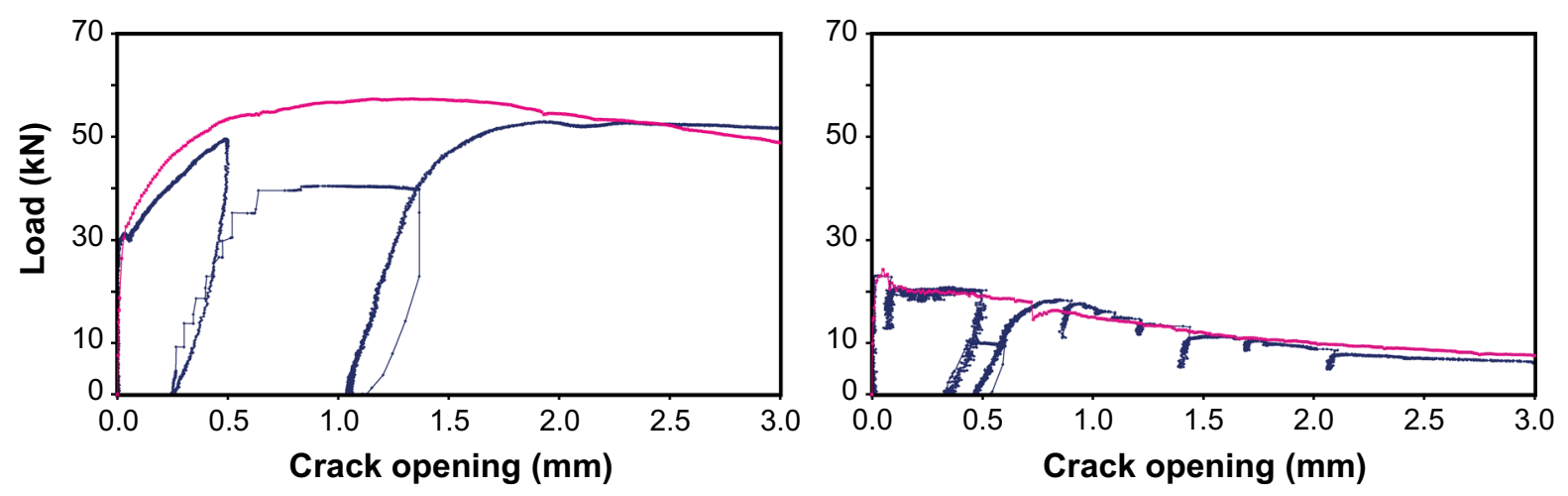

Fig. 3 Load vs crack opening curves at the characterization test, compared with the post creep response for FRC with flexural behavior showing hardening (left) or softening (right). Adapted from [16]

\subsubsection{Bending in linear elements with rebars}

Where FRC contributes with reinforcing bars to bending resistance at ULS (by means of its residual strength in the cracked section), at service conditions FRC allows to reduce the crack spacing and opening [30]. The latter depends on the residual tensile strength at SLS $\left(f_{\mathrm{Ftsm}}\right.$ in MC 2010) and on the percentage of longitudinal rebars $[8,31]$. In a properly designed structure, with controlled cracks, the residual stresses supported by FRC in the crack faces will be close to the serviceability residual strength $\left(f_{\mathrm{Ftsm}}\right)$ and the stress in the rebars $\left(\sigma_{s}\right)$ will be reduced in service conditions (with respect to RC). Figure 4 shows a schematic view of the evolution of the neutral axis and the expected variation in strains and stresses in the section.

By considering a beam under bending and long term loading, a possible increase of FRC deformation due to creep, in both compression and tension (or crack opening), provokes a stress transfer from FRC to rebars. However, the stress increase in rebars is very limited since, in regular beams, the percentage of the tensile stress taken by fibers usually ranges between 10 and $20 \%$.

Tan et al. [32], by testing beams in bending under long term loading, found that the crack widths for SFRC beams were generally smaller and stabilized at an earlier age with higher fiber contents.

Vasanelli et al. [31, 33] tested full scale RC beams reinforced with two types of fibers (steel and polyester) in short and long term bending condition, analyzing the influence of fibers on crack development in service conditions, with a sustained load equal to $50 \%$ of design ultimate load. In all cases short-term crack opening significantly reduced in FRC beams with respect to RC beams. Under long-term loading, experimental results showed that the number of cracks did not change during the constant sustained load and that crack width in FRC beams seems to stabilize after 10 months of exposure, while crack width in RC beams stabilized after a longer loading time (Fig. 5). Therefore, in addition to the initial smaller crack opening, also the crack opening increase over time was smaller in FRC beams.
Fig. 4 Evolution of the neutral axis and the expected variation in strains and stresses. a At initial cracking. b After creep effects

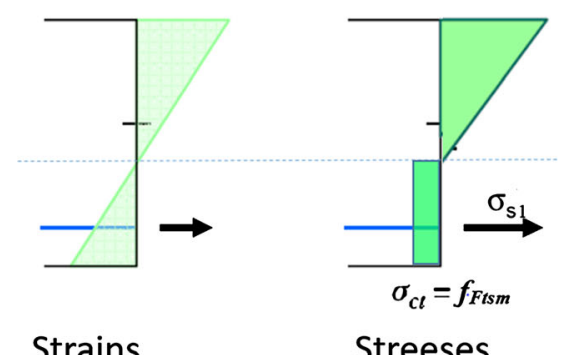

(a)

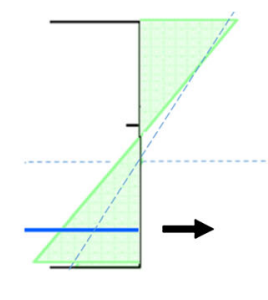

Strains

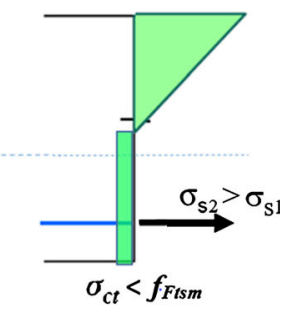

Streeses

(b) 
Fig. 5 Average crack width versus time measured on S1 beams of frame 2; ST beams were reinforced with steel fibers, POL beams were reinforced with polyester fibers, TQ was a beam without fibers [33]

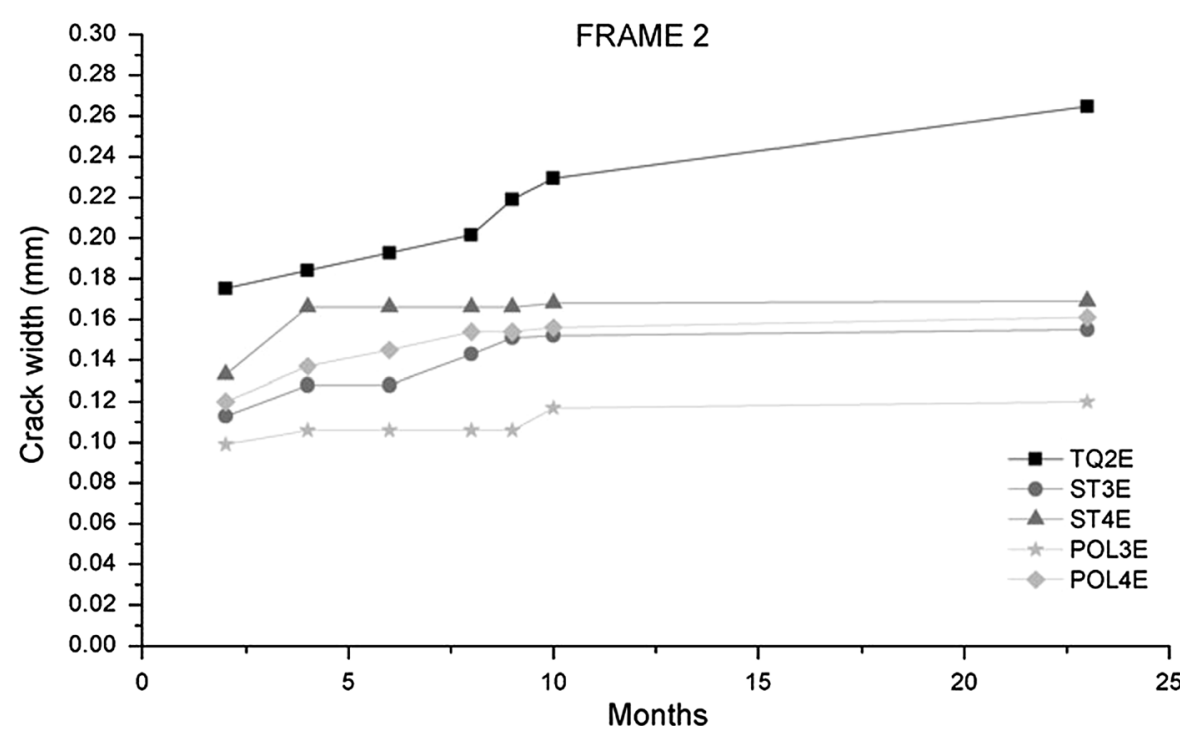

After the long term loading period (up to 70 months), all beams showed an ultimate capacity that was similar to the one observed at short-term loading, even if the FRC resistant contribution was relaxed due to FRC creep; therefore, FRC creep did not influence ULS capacity.

In summary, if FRC does not replace rebars, its effect is always favorable in controlling crack development and does not modify beam resistance at ULS. When FRC replaces part of the longitudinal rebars, it is necessary to verify the crack distance and width; however, the favorable effect of fibers hardly compensate the effect of the replaced rebars in bending.

\subsubsection{Shear in linear elements with rebars as bending reinforcement}

The use of stirrups for shear resistance is a classical solution but relatively expensive because it is laborwork demanding; the use of FRC for shear resistance is one of the most analyzed structural application in research studies (Fig. 6) [34, 35]. In fact, FRC enhances the shear resisting mechanisms in the beam. In fact, FRC increases the shear resistance in the compression zone as well as the dowel effect of the longitudinal rebars. However, when a shear crack develops, aggregate interlocking is a main shear resisting mechanism and the distributed action of fibers along all the crack length allows a better crack width control, leading to a stresses redistribution to other resisting mechanisms (Fig. 6). The prestressed

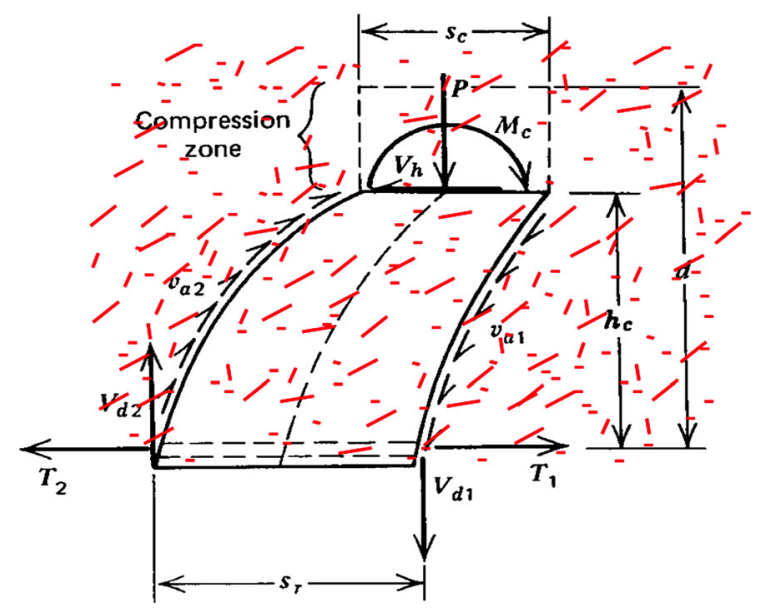

Fig. 6 Fiber effects on shear behavior of beams. Adapted from [42]

beams [36] or the wide-shallow beams [37] represent significant examples.

The most frequent FRC use in practice concerns the replacement of the minimum shear reinforcement (stirrups). However, shear cracks are not expected in service conditions as they form when the beam is approaching the ultimate shear load; therefore, creep effects are never important when FRC is adopted for shear behavior, both for beams without stirrups and, even more, for beams with stirrups.

In summary, FRC is a good solution as shear reinforcement and it is not influenced by FRC creep phenomena. 


\subsection{Bi-dimensional elements}

Slabs and walls are nowadays typical 2D elements where FRC may provide significant advantages to the structural behavior.

Slabs on grade are one of the most fibers consuming applications for industrial floors [38]. This was possible well before the publication of the main building codes because these slabs were erroneously considered as non-structural elements only because they are at "ground level" and their collapse does not imply danger for the human life. However, there are no doubts about their structural behavior when considering the presence of shelves with heavy loads in seismic areas, where the concrete floors act as foundations (their collapse represents a serious danger for people present in the area). However, cracks are generally not expected in service conditions in these slabs and they are accepted only during severe loading conditions, as it happens during earthquakes; therefore, creep is not a main issue in these structures.

Other cases that are of increasing interest in recent years are elevated two-ways slabs [39, 40], due to the smaller reinforcement ratio needed. Here fibers can substitute most of the traditional reinforcement and, due to the high degree of redundancy, these structures allow a significant stress redistribution. However, the use of FRC without rebars hardly satisfies ductility requirements (Eqs. 3 and 4) for the expected failure mode, as slabs are very stiff structures and then deformability is usually low. Therefore, a minimum "anti-collapse" reinforcement is generally present along the lines connection columns; recent studies clearly evidenced that an optimized reinforcement requires the addition of further rebars to provide resistance to peak moments present on the columns [40] (Fig. 7). In summary, the high degree of redundancy allows a more stable crack development and a stress redistribution (due to stress relaxation provoked by creep) is also possible between FRC and rebars that are usually present. Once again, with the exception of slabs with very low amounts of rebars (which hardly satisfy ductility requirements), FRC creep is not a main issue for these structures.

As far as one-way slabs are concerned, the only stress redistribution is present along the wide section (as in a wide-shallow beam) width and FRC considerations described for linear elements should be applied (see Sect. 3.2).
Retaining walls is another 2D structure where the main reinforcement can be hardly substituted by FRC, as in linear elements. On the contrary, FRC may successfully replace secondary reinforcement required for stress redistribution; in this case, since FRC is not necessary for equilibrium requirements, FRC creep may generates a different stress redistribution but it will never provoke failure.

When walls support simultaneously bending and compression loads, the vertical loads can compensate the tensile stresses due to bending and the main reinforcement can be reduced. In these elements cracking phenomena may be significantly reduced and, with high vertical loads, even eliminated. Therefore, creep phenomena become negligible.

\subsection{Three-dimensional members}

Typical 3D FRC structures without rebars could be the tunnel linings, both conventional and segmental, where reinforcements may be not necessary due to the remarkable compressive stresses present during the service life. In these elements, FRC may substitute the minimum reinforcement, increase ductility in compression and collaborate to local and/or temporary tensile resistance, when necessary [41]. Since cracks are not expected in service conditions, creep phenomena can be neglected.

In the specific case of segmental lining, the most severe loading condition is often represented by the thrust jack action during TBM operations, which is a short term load. Another severe action may be present during the segment storage before placing the ring but, once again, this loading condition lasts a few months.

Specific considerations are necessary for some FRC structures characterized by a limited service live, as some mining applications, where a short time creep evolution may be better considered.

\section{Concluding remarks}

Fiber reinforcement effects in structural elements could be affected by long-term behavior of FRC related to fiber aging and creep behavior of FRC. The former may not be accepted in structural elements when safety is not guaranteed for the whole service life of the structure. 
$\underline{\text { Typical slab section }}$

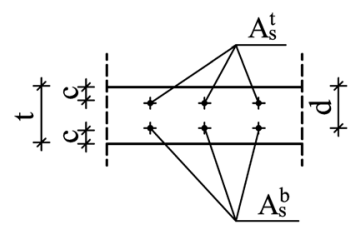

$\mathrm{c}=$ concrete cover

$\mathrm{t}=$ total slab thickness

$\mathrm{d}=\mathrm{t}-\mathrm{c}=$ effective depth

$\mathrm{A}_{\mathrm{s}}^{\mathrm{b}}=$ bottom rebars

$\mathrm{A}_{\mathrm{s}}^{\mathrm{t}}=$ top rebars

$\mathrm{L}_{\mathrm{p}}+\mathrm{d} \leq 2 \mathrm{~L}_{\mathrm{p}}$ (internal reinforement)

$\mathrm{L}_{\mathrm{p}}+0.5 \mathrm{~d} \leq 1.5 \mathrm{~L}_{\mathrm{p}}$ (border reinforement) (a)

\section{Bottom surface}

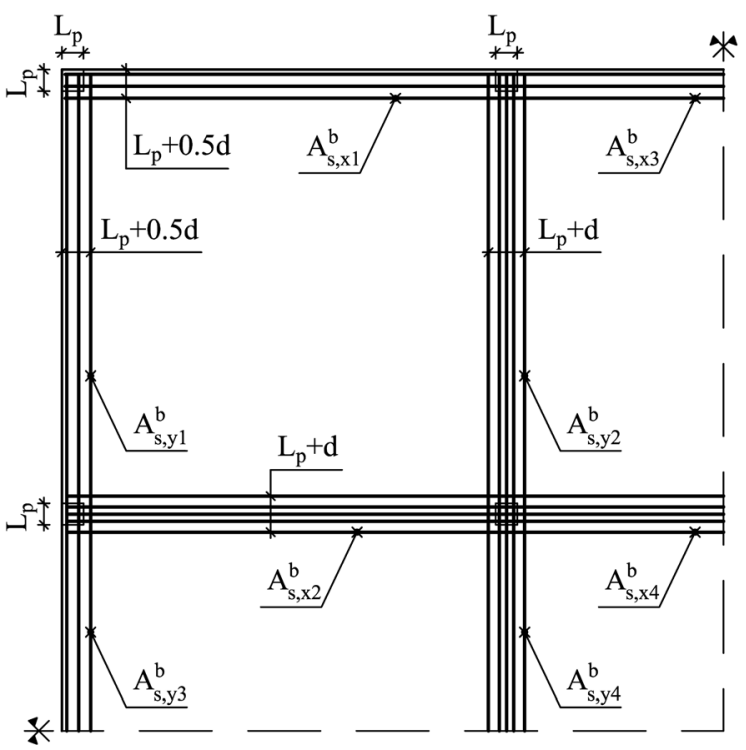

(c)

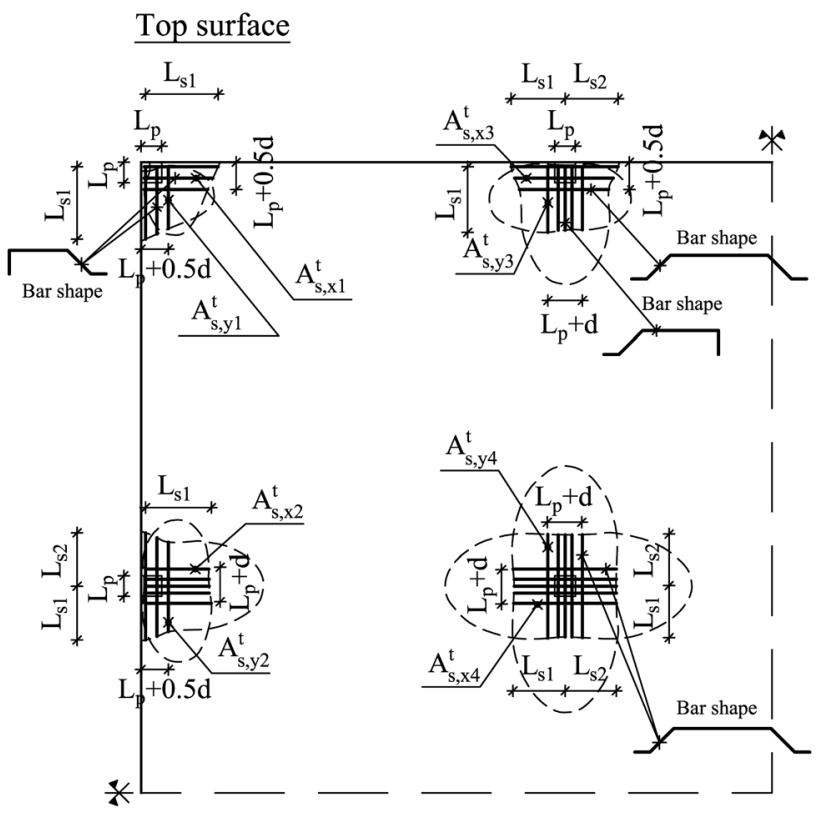

(b)

Typical top reinforcement detailing

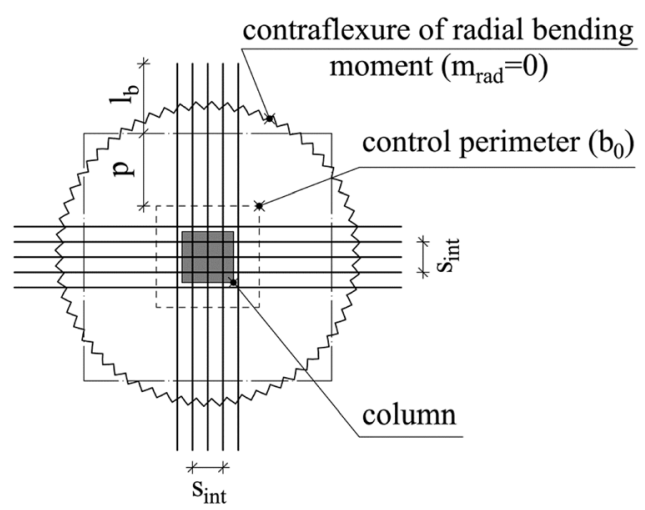

$\mathrm{p}=\min (2.5 \mathrm{~d} ;$ position of contraflexure line $)$

$\mathrm{b}_{0}=$ control perimeter (MC2010-clause 7.3.5.2) $1_{b}=$ bar development length

(d)

Fig. 7 Additional reinforcement detailing: a typical slab section; $\mathbf{b}$ top reinforcement layout; $\mathbf{c}$ bottom reinforcement layout; $\mathbf{d}$ rules for determining top reinforcement length [40]

Although creep behavior of FRC may represent in principle a major concern, real FRC structures of practical interest nowadays are not particularly affected by FRC creep. This is mainly due to the following main reasons:

- ductility requirements often impose the presence of conventional reinforcement, especially in linear 
elements but also in elevated slabs; rebars may take additional stresses due to FRC creep that are negligible in most cases.

- When FRC is adopted for substituting secondary reinforcement for stress redistribution, creep has a minor influence since FRC is not necessary for equilibrium.

- When using FRC as minimum reinforcement, cracks are not expected in service conditions and FRC creep assumes minor importance.

- In structures with high degree of redundancy, FRC creep may slightly affect stress redistribution.

- Critical structural aspects related to temporary loading are not affected by FRC creep.

- FRC creep in compression is very similar to creep of ordinary concrete since fibers do not play a significant role on long-term behavior.

FRC creep may become significant in structures with a low degree of redundancy, as linear elements with low reinforcement percentage, because of the limited stress redistribution. Before using FRC in these structures, creep tests have to be carried out in order to verify the long-term safety of the structure.

The effect of creep deformation should be considered specifically for the different resisting mechanism because it may be different between bending, shear, torsion, etc.

Acknowledgements This paper was written independently by the Authors who are grateful to all members of RILEM TC-261 FCC for their constructive discussions on the state-of-the-art on FRC creep as well as on the creep test methodologies.

\section{Compliance with ethical standards}

Conflict of interest The authors declare that they have no conflict of interest.

Open Access This article is distributed under the terms of the Creative Commons Attribution 4.0 International License (http:// creativecommons.org/licenses/by/4.0/), which permits use, duplication, adaptation, distribution and reproduction in any medium or format, as long as you give appropriate credit to the original author(s) and the source, provide a link to the Creative Commons license and indicate if changes were made.

\section{References}

1. Fib Model Code 2010 (2012). Final Complete Draft, fib bulletins 65 and 66, March 2012-ISBN 978-2-88394-105-2 and April 2012-ISBN 978-2-88394-106-9
2. DAfStb - Deutscher Ausschuss für Stahlbeton (2012) Richtlinie Stahlfaserbeton 11/2012 (German committee for reinforced concrete: DafStb Guideline Steel fibre reinforced concrete 11/2012), additions and changes to DIN EN 1992-1-1 in conjunction with DIN EN 1992-1-1/NA, DIN EN 206-1 in conjunction with DIN 1045-2 and DIN EN 13670 in conjunction with DIN 1045-3

3. CNR-DT 204/2006 Consiglio Nazionale delle Ricerche (2006) Guidelines for design, execution, and control of fibre-reinforced concrete structures

4. ACI 318-14: building code requirements for structural concrete and commentary. ACI Committee 318. American Concrete Institute (2014)

5. CEN/TC 250/SC 2/WG 1/TG 2 (2018) SFRC-steel fibre reinforced concrete, Annex to EN 1992-1-1, Eurocode 2 design of concrete structures-part 1-1: general rules and rules for buildings, work in progress

6. Serna P, Arango S, Ribeiro T, Núñez A, García-Taengua E (2009) Structural cast-in-place SFRC: technology, control criteria and recent applications in Spain. Mater Struct 42(9):1233-1246

7. Di Prisco M, Plizzari G, Vandewalle L (2014) Structural design according to fib MC 2010: comparison between RC and FRC elements. In: Proceedings of the FRC 2014 Joint ACI-fib International Workshop, Montreal, Canada, pp 69-87

8. Vandewalle L (2000) Cracking behaviour of concrete beams reinforced with a combination of ordinary reinforcement and steel fibres. Mater Struct 33:164-170

9. Cunha VM, Barros JA, Abrishambaf A (2017) Time-dependent flexural behaviour of SFRSCC elements. In: Serna $\mathrm{P}$, Llano-Torre A, Cavalaro S (eds) Creep behaviour in cracked sections of fibre reinforced concrete. RILEM Bookseries, vol 14. Springer, Dordrecht

10. Llano-Torre A, Arango SE, García-Taengua E, Martí-Vargas JR, Serna P (2017) Influence of fibre reinforcement on the long-term behaviour of cracked concrete. In: Serna P, Llano-Torre A, Cavalaro S (eds) Creep behaviour in cracked sections of fibre reinforced concrete. RILEM Bookseries, vol 14. Springer, Dordrecht

11. Hannant DJ (1998) Durability of polipropylene fibers in portland cement-based composite: eighteen years of data. Cem Concr Res 28(12):1809-1817

12. Bentur A, Mindess S (2007) Fibre reinforced cementitious composites, 2nd edn. Taylor and Francis, Routledge

13. ASTM C512/C512M-15 (2015). Standard test method for creep of concrete in compression. ASTM International, West Conshohocken, PA. https://doi.org/10.1520/c0512_ c0512m-15, www.astm.org

14. Balaguru P, Ramakrishnan V (1988) Properties of fibre reinforced concrete: workabilty, behaviour under long-term loading and air-void characteristics. ACI Mater J 85(3):189-196

15. Serna P, Llano-Torre A, Cavalaro S (eds) (2016) Creep behaviour in cracked sections of fibre reinforced concrete. RILEM Bookseries, vol 14. Springer, Dordrecht

16. Arango SE et al (2012) A test method to characterize flexural creep behavior of pre-cracked FRC specimens. Exp Mech 52(8):1067-1078

17. Bernard ES (2004) Creep of cracked fibre reinforced shotcrete panels. In: Bernard (ed) Shotcrete: more engineering developments, pp 47-57 
18. Larive C, Rogat D, Chamoley D, Welby N, Regnard A (2015) Creep behaviour of fibre reinforced sprayed concrete. In: SEE Tunnel: Promoting Tunneling in SEE Region, ITA WTC 2015 Congress and 41st General Assembly May 22-28, 2015, Dubrovnik, Croatia

19. CEN. EN 14889-2:2006. Fibres for concrete-part 2: polymer fibres-definitions, specifications and conformity. European Committee for Standardization

20. CEN. EN 14030:2001:2003. Geotextiles and geotextile-related products - screening test method for determining the resistance to acid and alkaline liquids (ISO/TR 12960:1998, modified). European Committee for Standardization

21. CEN. EN 14649:2005. Precast concrete products-test method for strength retention of glass fibres in cement and concrete (SIC TEST). European Committee for Standardization

22. CEN. EN 14651:2007. Test method for metallic fibre concrete. Measuring the flexural tensile strength (limit of proportionality (LOP), residual). European Committee for Standardization

23. Bast T, Eder A, Kusterle W (2007) Kriechversuche an kunststoffmakrofaserbetonen-Untersuc hungen zum langzeitver-halten von faserbetonen unter biegezugbeanspruchung. Ein Zwischen bericht. Faserbeton Beiträge zum 11. Vilser Baustofftag, pp 32-35

24. Barragán BE, Zerbino RL (2008) Creep behavior of cracked steel fibre reinforced concrete beams. In: Proceedings of the 7th Int. RILEM Symp. on Fibre Reinforced Concrete: Design and Applications (BEFIB 2008), Chennai, pp 577-586

25. Kanstad T, Zirgulis G (2012) Long-time creep testing of pre-cracked fibre reinforced concrete beams. In: 8th RILEM International Symposium on Fibre Reinforced Concrete BEFIB 2012. 8th RILEM International Symposium on Fibre Reinforced Concrete (BEFIB 2012), Guimaraes, Portugal, pp 195-196

26. Zhao G, Di Prisco M, Vandewalle L (2014) Experimental investigation on uniaxial tensile creep behavior of cracked steel fiber reinforced concrete. Mater Struct 2014(48):3173-3185

27. Babafemi AJ, Boshoff WP (2015) Tensile creep of macrosynthetic fibre reinforced concrete (MSFRC) under uniaxial tensile loading. Cem Concr Compos 5:62-69

28. Kusterle W (2009) Viscous material behavior of solidscreep of polymer fiber reinforced concrete. In: 5 th Central European Congress on Concrete Engineering, Baden
29. García-Taengua E, Arango S, Martí-Vargas J, Serna P (2014) Flexural creep of steel fiber reinforced concrete in the cracked state. Constr Build Mater 2014(65):321-329

30. Balazs GL, Kovac I (2004) Effect of steel fibres on the cracking behaviour of RC members. In: Proceedings of 6th RILEM Symposium on Fibre-reinforced ConcretesBEFIB 2004, Varenna, Italy, 20-22 September 2004

31. Vasanelli E, Micelli F, Aiello MA, Plizzari G (2014) Crack width prediction of FRC beams in short and long term bending condition. Mater Struct 47(1-2):39-54

32. Tan KH, Paramasivam P, Tan KC (1995) Cracking characteristics of reinforced steel fibre concrete beams under short and long-term loadings. Adv Cem Based Mater 2:127-137

33. Vasanelli E, Micelli F, Aiello MA, Plizzari G (2013) Long term behavior of FRC flexural beams under sustained load. Eng Struct 56:1858-1867

34. fib Bulletin 57 (2010) Shear and punching shear in RC and FRC elements. In: Minelli F, Plizzari G (eds) Proc. Workshop held in Salò (Brescia, Italy) on 15-16 October. ISSN 1562-3610, ISBN 978-2-88394-097-0, 268 pp

35. Cuenca E, Conforti A, Minelli F, Plizzari G, Navarro Gregori J, Serna P (2018) A material-performance-based database for FRC and RC elements under shear loading. Mater Struct. https://doi.org/10.1617/s11527-017-1130-7

36. Conforti A, Minelli F, Plizzari GA (2013) Wide-shallow beams with and without steel fibres: a peculiar behaviour in shear and flexure. Compos B Eng 51:282-290

37. Cuenca E, Serna P (2013) Shear behaviour of prestressed precast beams made of self-compacting fibre reinforced concrete. Constr Build Mater 45:145-156

38. Sorelli L, Meda A, Plizzari GA (2006) Steel fibre concrete slabs on grade: a structural matter. ACI Struct J 103(4):551

39. Salehian H, Barros JAO (2011) Design of elevated steel fibre reinforced self-compacting concrete slabs. Technical report 11-DEC/E-30, Department of Civil Engineering, School Engineering, University of Minho, Portugal

40. Facconi L, Plizzari G, Minelli F (2018) Elevated slabs made of hybrid reinforced concrete: proposal of a new design approach in flexure. Struct Concr. https://doi.org/10.1002/ suco. 201700278

41. Tiberti G, Minelli F, Plizzari G (2014) Reinforcement optimization of fiber reinforced concrete linings for conventional tunnels. Compos B Eng 58:199-207

42. Park R, Paulay T (1975) Reinforced concrete structures. Print ISBN: 9780471659174, Online ISBN: 9780470172834. Wiley. https://doi.org/10.1002/9780470172834 